\title{
Field Plot Technique Affects Snap Bean Yield Evaluation
}

\author{
Gavin R. Sills ${ }^{1}$ and James Nienhuis ${ }^{2}$ \\ Horticulture Department, University of Wisconsin, Madison, WI 53706 \\ Additional index words. Phaseolus vulgaris, French bean, optimum plot size, plant density, harvest method
}

\begin{abstract}
The interactive effects of genotypes, plant population densities, and harvest methods on snap bean (Phaseolus vulgaris L.) yield evaluation were investigated using a split-split plot factorial arrangement of treatments at two locations Six snap bean processing cultivars were grown at 5.5, 11, and 22 plants $/ \mathrm{m}^{2}$ and harvested either by machine or by hand. Each' of three commercial seed companies provided two cultivars, one of which was described as "good" and the other as "poor" for machine harvesting. Genotype $\times$ harvest method interactions were not significant for pod count, but were significant when yield was evaluated as pod weight. This latter interaction was explained by a single-degree-of-freedom contrast of genotypes $\times$ ("good" vs. "poor" harvestability). Genotype $\times$ density and genotype $\times$ density $\times$ location interactions were significant for both pod count and weight. The density $\times$ harvest method interaction was nonsignificant for both yield variables. These results suggest that breeders can evaluate yield of genotypes using either hand or machine harvest but should use plant population densities appropriate to commercial production. Optimum plot size for snap bean yield evaluations at these locations under the various conditions imposed were estimated.
\end{abstract}

The extent to which early generation snap bean breeding lines are evaluated for yield is determined primarily by limited seed supplies and the costs associated with testing. Both of these factors are subject to limited control by the plant breeder. However, alterations in field-plot design factors, such as plant population density, harvest method, and plot size, are typically under greater control by the plant breeder. Nevertheless, to design field plots for optimal efficiency, the effects and interactions associated with design factors must be understood.

Plant population density has been shown to influence snap bean yield greatly (Mack and Varseveld, 1982; Stang et al., 1979). Likewise, whether plots are harvested by machine or by hand may affect estimates of the yield potential of a breeding line. But, breeders are less interested in optimizing yields during evaluation than in ensuring that the rank of genotypes is indicative of their yield potential. Therefore, in evaluating germplasm of possibly limited seed supply for yield potential, snap bean breeders need information regarding the interaction of genotypes with field plot variables. In addition, how to best allocate limited seed resources to experimental units is a concern. The objectives of this study were to investigate the interactive effects of genotypes, plant density, and harvest methods, and to estimate the optimum plot size for yield evaluation.

\section{Materials and Methods}

Agronomic data. The experiment was conducted at two locations at the Univ. of Wisconsin Research Station at Hancock in 1991. There were four replications at the field planted 12 June (location 1) and three replications at the field planted 26 June (location 2). A split-split plot with replicates in blocks experimental design was used. Main plots were six processing snap bean genotypes (Table 1). Two genotypes, one of which was described as "good" and the other as "poor" in terms of efficiency of machine harvestability, were obtained from each of three seed companies

Received for publication 16 Apr. 1992. Accepted for publication 22 Jan. 1993. The cost of publishing this paper was defrayed in part by the payment of page charges. Under postal regulations, this paper therefore must hereby be marked advertisement solely to indicate this fact.

'Graduate Research Assistant.

${ }^{2}$ Assistant Professor. and used as the experimental material. Sub-plots were plant densities of $5.5,11$, and 22 plants $/ \mathrm{m}^{2}$. Densities were varied only by within-row spacing. Genotypes were planted in $91-\mathrm{cm}$ rows and thinned to $91 \times 20-, 91 \times 10-$, and $91 \times 5$-cm arrangements. Subsub-plots were the harvest methods, which included once-over machine and hand harvests. Machine harvest was performed with a four-row harvester (Chisholm-Ryder, Niagra Falls, N.Y.) modified to harvest only two rows.

Experimental units were four-row plots $3.7 \mathrm{~m}$ long. Harvest date was determined according to the combined length of 10 seeds sampled from pods selected at random (Mullins and Coffey, 1990). For machine-harvested plots, a $3.05-\mathrm{m}$ section of the second row was combined. For hand-harvested plots, two 1.52-m subsamples of the second row were pulled, bundled, and processed. Processing included sieving, weighing, and counting pods.

Statistical analysis. Data were analyzed by the General Linear Model procedure of SAS (SAS Institute, 1988). For analyses including harvest methods, subsamples within hand-harvested plots were combined to give plot sizes equal to machine-harvested plots. Locations and harvest methods were considered fixed effects, while densities and genotypes were considered random effects. Pod count data were used to calculate Smith's coefficient of soil heterogeneity (Smith, 1938) by the method described by

Table 1. Experimental design variables.

\begin{tabular}{|c|c|c|}
\hline Factor & Number & Levels \\
\hline \multirow[t]{2}{*}{ Location } & 2 & Location $1,(4$ reps) \\
\hline & & Location 2 (3 reps) \\
\hline \multirow[t]{6}{*}{ Genotype } & 6 & Espada $^{z}$ \\
\hline & & BBL $92^{z}$ \\
\hline & & $\mathrm{BX}-156^{2}$ \\
\hline & & Hystyle $^{y}$ \\
\hline & & Labrador $^{\mathrm{y}}$ \\
\hline & & Benton $^{y}$ \\
\hline \multirow[t]{3}{*}{ Density } & 3 & $91 \times 20 \mathrm{~cm}$ \\
\hline & & $91 \times 10 \mathrm{~cm}$ \\
\hline & & $91 \times 5 \mathrm{~cm}$ \\
\hline \multirow[t]{2}{*}{ Harvest } & 2 & Hand harvest \\
\hline & & Machine harvest \\
\hline
\end{tabular}


Koch and Rigney (1951). The time required to perform all aspects of this experiment was recorded and the optimum plot size was calculated as:

$$
X_{\mathrm{OPT}}=\mathrm{b}\left(\mathrm{K}_{1}+\mathrm{K}_{\mathrm{g}} \mathrm{A}\right) /(1-\mathrm{b})\left(\mathrm{K}_{2}+\mathrm{K}_{\mathrm{g}} \mathrm{B}\right)
$$

where $\mathrm{X}_{\mathrm{OPT}}$ is the number of the smallest units in the optimum plot size, $b$ is the coefficient of soil heterogeneity, $K_{1}$ is the cost per unit number, $\mathrm{K}_{2}$ is the cost per unit test area, $\mathrm{K}_{\mathrm{g}}$ is the cost per unit of guard area, $\mathrm{A}$ is the end guard area, and $\mathrm{B}$ is the ratio of side guard area to test area. Cost was measured in terms of worker hours. The smallest unit for machine-harvested plots was $2.77 \mathrm{~m}^{2}$ (3.05-m-long row) and for hand-harvested plots was $1.39 \mathrm{~m}^{2}(1.52-$ m-long row).

\section{Results}

At location 1, genotypes were harvested 15-20 Aug. at between 117- and 127-mm seed length. At location 2, genotypes were harvested 3-6 Sept. at between 125 and $140 \mathrm{~mm}$. Due to the variation in pod size among genotypes and the advanced maturity of the plants at harvest, yield data are presented in terms of weight and number of pods larger than sieve size three $(8 \mathrm{~mm})$. The average percentage of pods larger than sieve size three across all genotypes at locations 1 and 2 was $89 \%$ and $91 \%$, respectively.

There was a highly significant genotype $\times$ harvest method interaction for pod weight analyzed over locations. Errors were normally distributed. A single-degree-of-freedom contrast, harvest method x ("good" vs. "poor'? harvestability), was used to partition the genotype $\times$ harvest method sums of squares. This contrast was highly significant $(P \leq 0.01)$ and the remaining variation with 4 df was nonsignificant $(P \geq 0.05)$ (Fig. 1).

An analysis of variance (ANOVA) of pod count combined over locations gave normally distributed errors and showed that genotypes did not interact significantly with harvest methods (Table 2 ). There were significant genotype $\times$ density, genotype $\times$ location, and genotype $\times$ density $\times$ location interactions. All other second-

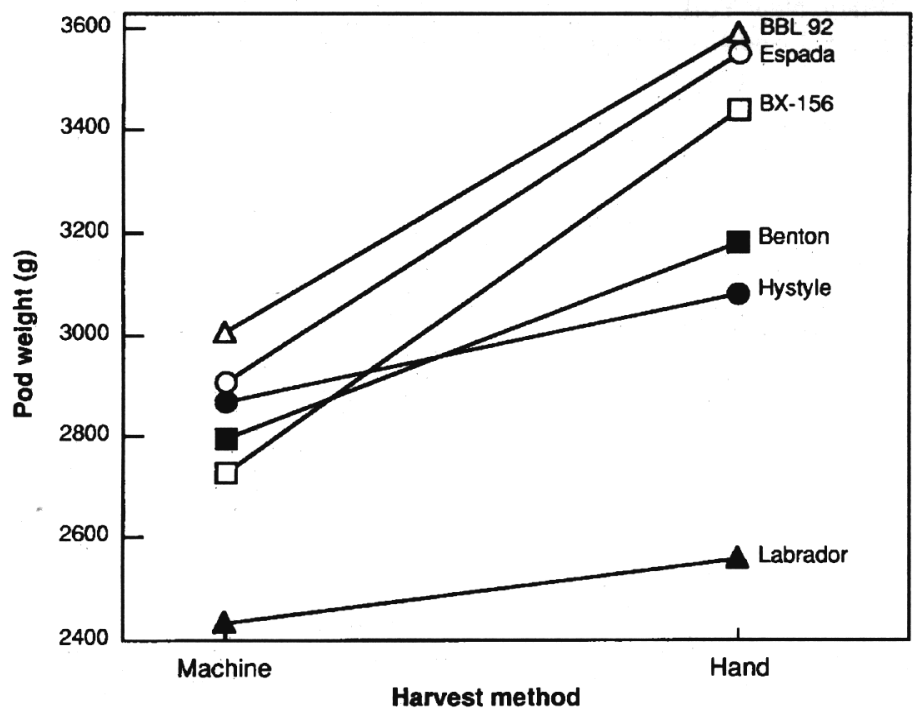

Fig. 1. Genotype $\times$ harvest method interaction including harvest method $\times$ ("good" vs. "poor" harvestability) contrast for pod weight analyzed over locations. \begin{tabular}{lcrrr} 
Source & DF & SS & \multicolumn{1}{c}{ MS } & \multicolumn{1}{c}{ F } \\
\hline Genotype $\times$ harvest method & 5 & $3,139,306$ & 627,861 & $4.13^{* *}$ \\
HM $\times$ ("good" vs. "poor") & 1 & $1,952,557$ & $1,952,557$ & $12.85^{* *}$ \\
Remainder & 4 & $1,186,749$ & 296,687 & $1.93 \mathrm{NS}$ \\
\hline
\end{tabular} $\frac{\text { Remainder }}{{ }_{\mathrm{Ns},}^{*} \text { Not significant and significant } \mathrm{F} \text { at } P \leq 0.05 \text { and } 0.01 \text {, respectively. }}$
Table 2. Combined analysis of variance for pod weight and pod count with mean squares and $\mathrm{F}$ tests.

\begin{tabular}{|c|c|c|c|c|c|}
\hline \multirow[b]{2}{*}{$\begin{array}{l}\text { Source } \\
\text { of variation }\end{array}$} & \multirow[b]{2}{*}{$\mathrm{df}$} & \multicolumn{2}{|c|}{ Pod wt } & \multicolumn{2}{|c|}{ Pod count } \\
\hline & & $\begin{array}{c}\text { Mean } \\
\text { square }\end{array}$ & $\mathrm{F}$ & $\begin{array}{l}\text { Mean } \\
\text { square }\end{array}$ & $\mathrm{F}$ \\
\hline Location (L) & 1 & $2,300,048$ & NS & 434,435 & $* * *$ \\
\hline $\operatorname{Rep} / \mathrm{L}$ & 5 & $2,170,401$ & & 21,718 & \\
\hline Genotypes (G) & 5 & $3,183,095$ & $* * *$ & 40,152 & $* * *$ \\
\hline $\mathrm{L}^{*} \mathrm{G}$ & 5 & 857,211 & $* *$ & 14,619 & $* * *$ \\
\hline Error (a) & 25 & 268,917 & & 4,260 & \\
\hline Density (D) & 2 & $13,303,161$ & $* * *$ & 354,607 & $* * *$ \\
\hline $\begin{array}{l}\mathrm{L} * \mathrm{D} \\
* * *\end{array}$ & 2 & 3,585 & NS & 14,384 & \\
\hline $\mathrm{G}^{*} \mathrm{D}$ & 10 & 423,958 & $* * *$ & 11,294 & $* * *$ \\
\hline$L * G * D$ & 10 & 233,664 & $*$ & 4,885 & $* *$ \\
\hline Error (b) & 60 & 137743 & & 2,338 & \\
\hline Harvest(H) & 1 & $11,125,367$ & $* * *$ & 81,375 & $* * *$ \\
\hline $\mathrm{L} * \mathrm{H}$ & 1 & $1,126,743$ & $* * *$ & 5,912 & NS \\
\hline$G^{*} \mathbf{H}$ & 5 & 627,861 & $* * *$ & 5,121 & $*$ \\
\hline $\mathrm{D}^{*} \mathrm{H}$ & 2 & 146,425 & NS & 4,199 & NS \\
\hline$L * G * H$ & 5 & 343,002 & $*$ & 3,295 & NS \\
\hline $\mathrm{L} * \mathrm{D} * \mathrm{H}$ & 2 & 135,371 & NS & 1,825 & NS \\
\hline $\mathrm{G}^{*} \mathrm{D}^{*} \mathrm{H}$ & 10 & 248,583 & NS & 2,324 & NS \\
\hline$L * G * D * H$ & 10 & 81,100 & NS & 1,216 & NS \\
\hline \multirow[t]{2}{*}{ Error (c) } & 89 & 151,900 & & 2,508 & \\
\hline & & $\mathrm{CV}=12.9$ & & \multicolumn{2}{|c|}{$\mathrm{CV}=12.26$} \\
\hline
\end{tabular}

${ }^{*, * * * * * *}$ Significant $\mathrm{F}$ at $P \leq 0.10,0.05$, and 0.01 , respectively.

and third-order interactions were nonsignificant for pod count.

Coefficients of soil heterogeneity (b) for each harvest method combined over locations were determined by regression analyses. The coefficients for hand and machine harvest were $0.41 \pm 0.13$

Table 3. Cost estimates in worker-hours for determining pod count of snap beans planted at three densities and using two harvest methods.

\begin{tabular}{|c|c|c|c|c|c|c|}
\hline \multirow[b]{3}{*}{ Task } & \multicolumn{3}{|c|}{ Machine harvest } & \multicolumn{3}{|c|}{ Hand harvest } \\
\hline & \multicolumn{3}{|c|}{ In-row spacing $(\mathrm{cm})$} & \multicolumn{3}{|c|}{ In-row spacing $(\mathrm{cm})$} \\
\hline & 5 & 10 & 20 & 5 & 10 & 20 \\
\hline Seed preparation & 0.005 & 0.003 & 0.002 & 0.002 & 0.001 & $\overline{0.001}$ \\
\hline Field preparation & 0.006 & 0.006 & 0.006 & 0.003 & 0.003 & 0.003 \\
\hline Planting & 0.032 & 0.021 & 0.015 & 0.016 & 0.010 & 0.007 \\
\hline Thinning & 0.050 & 0.025 & 0.013 & 0.023 & 0.013 & 0.006 \\
\hline Harvest & 0.048 & 0.037 & 0.031 & 0.017 & 0.011 & 0.008 \\
\hline Pulling pods & & & & 0.161 & 0.140 & 0.118 \\
\hline Counting pods & $\underline{0.083}$ & $\underline{0.074}$ & $\underline{0.059}$ & $\underline{0.046}$ & $\underline{0.040}$ & $\underline{0.034}$ \\
\hline $\mathrm{K}_{2}^{\mathrm{z}}$ & 0.224 & 0.165 & 0.124 & 0.270 & 0.218 & 0.177 \\
\hline Planting plans & 0.008 & & & 0.008 & & \\
\hline Plot stakes & 0.003 & & & 0.003 & & \\
\hline Harvest & 0.032 & & & & & \\
\hline Sieving & 0.056 & & & 0.056 & & \\
\hline Data manipulation & $\underline{0.049}$ & & & $\underline{0.049}$ & & \\
\hline $\mathrm{K}_{1}^{\mathrm{y}}$ & 0.147 & & & 0.115 & & \\
\hline $\mathrm{K}_{\mathrm{g}}^{\mathrm{x}}$ & 0.103 & 0.065 & 0.045 & 0.047 & 0.029 & 0.017 \\
\hline
\end{tabular}


and $0.55 \pm 0.15$, respectively. These two estimates of $b$ were found to be not significantly different by way of an extra sums of squares test (Draper and Smith, 1981). Therefore, the average b value was determined and the errors of the two estimates were pooled. Thus, for the Hancock Research Station, the coefficient of soil heterogeneity for snap bean pod counts is $0.48 \pm 0.11$. Costs in workerhours for the various tasks involved in conducting a hand harvest were higher than those for machine harvest under the conditions imposed by this experiment (Table 3).

\section{Discussion}

ANOVA: Main effects and interactions. Although the harvest method main effect was highly significant, the genotype $\mathrm{x}$ harvest method interaction for pod count was only significant at $P \leq 0.1$, suggesting that discrimination among snap bean genotypes for yield in terms of pod number will be unaffected by the harvest method used. Therefore, evaluating yield of machine harvested plots is the better alternative because the time required (hence, cost per plot) for machine harvest is lower than for hand harvest.

A highly significant genotype $\times$ harvest method interaction for pod weight was explained entirely by a single-degree-of-freedom contrast that showed that the pod weight yield of "good" machineharvest genotypes was reduced much less by machine harvest than was that of genotypes of "poor" harvestability. The machine $\times$ ("good" vs. "poor" machine harvestability) interaction occurred for pod weight and not for pod count. The pod weight reduction in "poor" vs. "good" harvestability genotypes probably is due to a preferential loss of larger and heavier pods over smaller and lighter ones. The ultimate cause of yield differences due to machine harvestability among the genotypes may be due to differences in plant architecture, such as plant height, pod position within the canopy, and the extent and angle of branching.

Pod weight increased linearly with increased plant density, as was the case in many previous studies (e.g., Mack and Varseveld, 1982; Mullins et al., 1988; Smittle, 1976). At both locations, the density main effect on pod weight was partitioned into a highly significant linear effect and anonsignificant quadratic effect. Similarly, pod count increased linearly with increased plant density; however, at location 1 , there was a statistically discernible quadratic effect.

A highly significant genotype $\times$ density interaction indicates that the genotypes did not perform similarly relative to one another across the three densities tested. This difference may result from a differential effect of density on architectural traits of the genotypes. This effect has been observed in dry beans (Nienhuis and Singh, 1985) and merits further study in snap beans. The genotype $x$ density interaction varied significantly between locations 1 and 2 . For pod weight and pod count at each location, the genotype $\times$ density interaction was partitioned further via contrasts into a highly significant genotype $x$ density ${ }_{\text {(inear) }}$ effect and a nonsignificant genotype $\times$ density ${ }_{\text {(quadratic }}$ effect. The results indicate that the existence of the genotype $x$ density interaction is mainly due to the difference in the linear part of the yield responses to density of the different genotypes. Thus, breeders should evaluate for pod yield at a density appropriate to commercial production. However, seed quantity of early generation breeding material may limit the number of replications or test locations.

Hand harvest consistently yielded more pods and higher pod weights than machine harvest. But, the nonsignificant density $\times$ harvest method interaction obtained indicated that the difference between hand and machine harvest is consistent over plant densities.
Table 4. Estimated $\mathrm{X}_{\mathrm{OPT}}{ }^{\mathrm{z}}$ for evaluation of pod count by hand and machine harvest at three plant spacings and different values of $b .{ }^{y}$

\begin{tabular}{|c|c|c|}
\hline \multirow{2}{*}{$\begin{array}{l}\text { In-row } \\
\text { spacing }(\mathrm{cm}) \\
\end{array}$} & \multicolumn{2}{|c|}{ Harvest method } \\
\hline & Machine & Hand \\
\hline \multicolumn{3}{|c|}{$b=0.48$} \\
\hline 5 & 0.41 & 0.36 \\
\hline 10 & 0.58 & 0.44 \\
\hline 20 & 0.68 & 0.55 \\
\hline \multicolumn{3}{|c|}{$b=0.59^{x}$} \\
\hline 5 & 0.64 & 0.56 \\
\hline 10 & 0.90 & 0.69 \\
\hline 20 & 1.06 & 0.86 \\
\hline
\end{tabular}

${ }^{\mathrm{z}}$ Optimum plot size as a multiple of the smallest unit: 1.52 and $3.05 \mathrm{~m}$ for hand- and machine-harvested plots, respectively.

yCoefficient of soil heterogeneity.

${ }^{x} A$ conservative estimate of $b$ from $b=0.48+0.11$, its standard error.

Optimum plot size. For b values near 0.5, as in this study, optimum plot size estimates largely depend on the relative costs per plot vs. costs per unit test area. Larger and smaller optimum plot size estimates will result from higher or lower levels of soil heterogeneity, respectively. Optimum plot size estimates for this study are unique to the density $\times$ harvest method combination because of the different amounts of time required at each level of these factors (Table 4). The estimated optimum plot sizes are all smaller than what was used in this investigation. Optimum plot size estimates from cucumbers (Cucumis sativus L.) (Smith and Lower, 1978) and peas (Pisum sativum L.) (Zuhlke and Gritton, 1969) also indicated that relatively small plots would be efficient for estimating fruit yield. Estimates of soil heterogeneity are associated with large standard errors. A more conservative estimate of $b$ may be prudent. Nonetheless, our results suggest that the plot sizes used in this study were unnecessarily large.

\section{Literature Cited}

Draper, N.R. and H. Smith. 1981. Applied regression analysis. 2nd ed. Wiley, New York.

Koch, E.J. and J.A. Rigney. 1951. A method of estimating optimum plot size from experimental data. Agron. J. 43: 17-21.

Mack, H.J. and G.W. Varseveld. 1982. Response of bush snap beans (Phaseolus vulgaris L.) to irrigation and plant density. J. Amer. Soc. Hort. Sci. 107:286-290.

Mullins, C.A. and D.L. Coffey. 1990. Snap bean quality as affected by cultivar and harvest. J. Prod. Agr. 3: 131-135.

Mullins, C.A., R.A. Straw, and D.L. Coffey. 1988. Production of snap beans as affected by soil tillage method and row spacing. J. Amer. Soc. Hort. Sci. 113:667-669.

Nienhuis, J. and S.P. Singh. 1985. Effects of location and plant density on yield and architectural traits in dry beans. Crop Sci. 25:579-584.

SAS Institute. 1988. SAS/STAT user's guide. 4th ed. SAS Inst., Cary, N.C.

Smith, H.F. 1938. An empirical law describing heterogeneity in the yield of agricultural crops. J. Agr. Sci. 28:-23.

Smith, O.S. and R.L. Lower. 1978. Field plot techniques for selecting increased once over harvest yields in pickling cucumbers. J. Amer. Soc. Hort. Sci. 103:92-94.

Smittle, D.A. 1976. Response of snap beans to irrigation, nitrogen fertilization, and plant population. J. Amer. Soc. Hort. Sci. 104:873-875.

Stang, J.R., H.J. Mack, and K.E. Rowe. 1979. Quantitative relation of bush snap bean (Phaseolus vulgaris L.) yields to plant population density. J. Amer. Soc. Hort. Sci. 104:873-875.

Zuhlke, T.A. and E.T. Gritton. 1969. Optimum plot size and shape estimates for pea yield trials. Agron. J. 61:905-908. 